\title{
Research
}

\section{Sword swallowing and its side effects}

\author{
Brian Witcombe, Dan Meyer
}

Sword swallowers know their occupation is dangerous. The Sword Swallowers' Association International (SSAI, www.swordswallow.org) recognises those who can swallow a non-retractable, solid steel blade at least two centimetres wide and 38 centimetres long. As we found only two English language case reports of injury resulting from sword swallowing, ${ }^{12}$ we explored the technique and side effects of this unusual practice.

\section{Methods}

We sent a letter to members and contacts of the association asking if they were willing for data held in its archives to be published and asking how they learnt the technique and how many swords they had swallowed in the previous three months. We did not send out a medical questionnaire but invited swallowers to describe any medical problems associated with sword swallowing. One medical adviser was approached after one swallower, injured during the course of the study, gave her consent, and a few close associates of one of the authors (DM) answered direct medical questions. We obtained written consent from everyone whose history is mentioned. We excluded cases in which injury was related to swallowing items other than swords, such as glass, neon tubes, spear guns, or jack hammers.

\section{Results}

We sent letters to 110 members or contacts of the association in 16 countries; 48 responded and 46 (41.8\%) consented to information being published (40 were men). The average age was 31 (range 16-64). Most were self taught and described how they learnt the technique. The average age when they learnt sword swallowing was 25 (range 13-46); nine learnt as teenagers. The average height was $176 \mathrm{~cm}$ (range 58-191 cm), average weight 79 $\mathrm{kg}$ (range 46-127 kg), and the longest sword swallowed was on average $60 \mathrm{~cm}$ (range $43-79 \mathrm{~cm}$ ). There was no apparent correlation between the length of the longest sword each person could swallow and their height (correlation coefficient 0.20 ) or weight $(-0.08)$. Twenty five had swallowed more than one sword at a time, five had swallowed more than 10 at a time, and one had swallowed 16 swords together (fig 1). Over the previous three months, the average number of swords swallowed was 43 (range of $0-300$ ).

Thirteen respondents did not volunteer any medical information, but 19 described sore throats, usually when they were learning to swallow, after performing too frequently, or when they were swallowing multiple or odd shaped swords. Lower chest pain, often lasting days, followed some performances and was usually treated by abstaining from practice. They rarely sought medical advice. Six suffered perforation of the pharynx or oesophagus. Three of these had surgery to the neck, one having a $1.5 \mathrm{~cm}$ laceration at the level of $\mathrm{D} 2$ and a pneumothorax, one a pinhole laceration at C6 and surgical emphysema, and the other having a pharyngeal tear. The perforations were treated conservatively in three patients, one of whom had a second
Department of Radiology, Gloucestershire Royal NHS Foundation Trust Glouceste GL1 3NN

Brian Witcombe consultant radiologist

Sword Swallowers' Association

International, 3729 Belle Oaks Drive, Antioch, Tennessee 37013, USA

Dan Meyer executive director Correspondence to: B Witcombe brian.witcombe@ glos.nhs.uk

BMJ 2006;333:1285-7

Risking sword throat 
perforation with aspiration of a neck abscess after further injury. Three others also had probable perforations, one of whom was told that a sword had "brushed" the heart, and one had pleurisy and another pericarditis after injury, suggesting extraoesophageal trauma. No one underwent thoracotomy, although one had a breadknife removed transabdominally. Sixteen mentioned intestinal bleeding, varying in quantity from melaena or finding some blood on a withdrawn sword to large haematemases necessitating transfusion. No members of the association had died from sword swallowing, but the cost of medical care was a concern with three members receiving medical bills around \$23000$\$ 70000$ (£12 000-£37 000; €18 000-€55 000).

\section{Discussion}

Our study relied on the memory of some of the 50 sword swallowers active in the English speaking world as well as some retired performers. Respondents could have exaggerated side effects, but it is more likely that details were overlooked. We did know of some incidents that involved non-respondents, and most serious events probably would have come to the attention of the association.

\section{Technique}

Some respondents swallowed a sword easily, but mastery for most required daily practice over months or years. The gag reflex is desensitised, sometimes by repeatedly putting fingers down the throat, but other objects are used including spoons, paint brushes, knitting needles, and plastic tubes before the swallower commonly progresses to a bent wire coat hanger. The performer must then learn to align a sword with the upper oesophageal sphincter with the neck hyperextended. The next step requires relaxation of the pharynx and oesophagus and particularly the horizontal fibres of cricopharyngeus, which are not usually under voluntary control. ${ }^{3}$ Devgan et al have shown that one swallower was able to reduce voluntarily the resting pressure of this sphincter by $10-20 \mathrm{~mm} \mathrm{Hg}{ }^{3}$ This swallower described having to "relax the muscles of his neck," and several swallowers mentioned not being able to perform when they could not "relax" or the throat "closing up" when sore. Huizinga ${ }^{4}$ described a swallower who "sucked in" the sword, and a lateral radiograph in Huizinga's paper shows the pharynx filled with air, but preliminary air swallowing is not invariable. Force must not be used and the clean sword is usually lubricated at least with saliva. One performer used butter, and one had to retire because of a dry mouth caused by medication.

Once the swallower has got the sword past the cricopharyngeal sphincter and relaxed the oesophagus, he or she must learn to control retching so the sword can be passed down to the cardia. The cardia lies about $40 \mathrm{~cm}$ from the teeth and the sword straightens the flexible and distensible oesophagus. Further progress depends not only on the swallower learning to relax the lower oesophageal sphincter and controlling retching but also on the shape of the stomach. The angle of the gastro-oesophageal junction and lesser curve vary, being obtuse in the vertically oriented stomach, particularly when it is full, and more acute in the high horizontal stomach often present in thickset

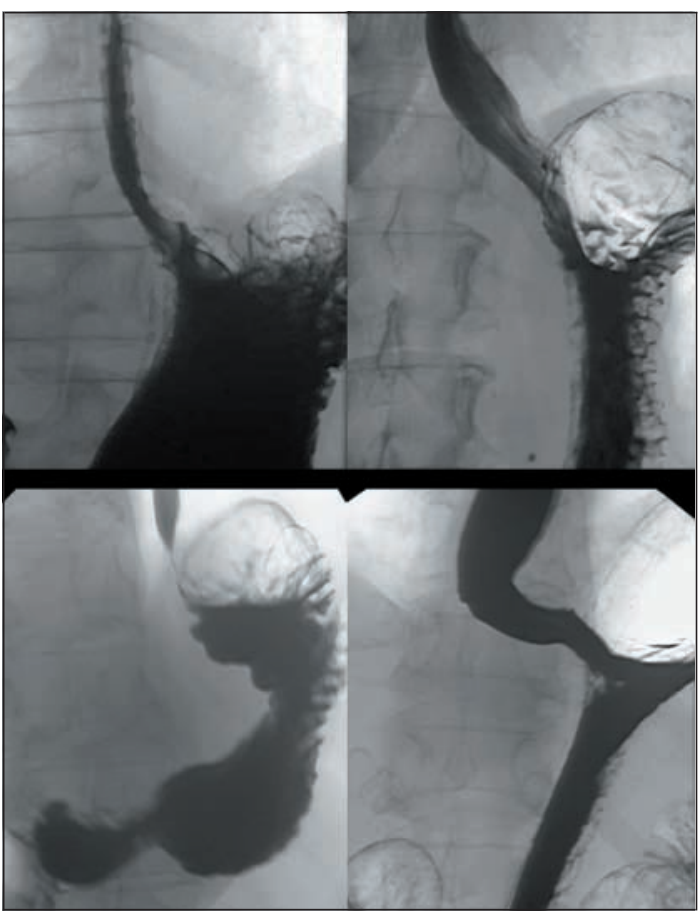

Fig 2 Barium radiographs showing the differing angle of the gastro-oesophageal junction in four individuals

individuals (fig 2). A $220 \mathrm{~cm}$ giant is said to hold the record for the longest swallowed sword $(82.5 \mathrm{~cm})$ and body build should have a bearing on what length of sword can pass. Nevertheless, we did not find any correlation between the longest sword an individual could swallow and their size, suggesting other factors are important.

Some experienced artistes add embellishments that increase danger. Some let the sword fall abruptly, a manoeuvre known as "the drop," controlling the fall of the sword with the muscles of the pharynx, and some invite members of the audience to move the sword. One lies prone on a bed of nails; one sometimes performs on a unicycle; and another under water.

\section{Side effects}

Sore throats-"sword throats"-occur when swallowers are learning, when performances are repeated frequently, or when odd shaped or multiple swords are used. Lower chest pains occur occasionally, most often after an obviously damaging swallow or when the "drop" is practised frequently. One performer described this pain after performing the drop 40 times a day in a state fair, and another described shoulder tip pain implying diaphragmatic irritation. Proprietary medicines are used for this problem, physicians are rarely consulted, and abstinence from swallowing swords is the main treatment.

Major injury is sometimes preceded by a previous painful performance, suggesting that minor injury may predispose to more serious damage. Occasionally a sword is difficult to advance or retract, presumably because of spasm or mucosal dryness related to nervousness or soreness. Overforceful efforts to move the sword may then cause trauma, and this resulted in oesophageal perforation in one performer. Several cases of perforation or severe haemorrhage occurred when swallowers used multiple or unusual swords or authors (DM) swords 
when a technical error was committed, often because of distraction. For example, one swallower lacerated his pharynx when trying to swallow a curved sabre, a second lacerated his oesophagus and developed pleurisy after being distracted by a misbehaving macaw on his shoulder, and a belly dancer suffered a major haemorrhage when a bystander pushed dollar bills into her belt causing three blades in her oesophagus to scissor. Of the 12 cases of probable perforation, including the two previously described in the literature, at least five involved the cervical or upper dorsal oesophagus with only one definite pharyngeal perforation. The other injuries were either lower down or the exact level of perforation was uncertain. All these patients survived, and no contacts of the association have died as a direct result of sword swallowing and no deaths have been reported in the medical literature. There is historical evidence elsewhere, however, and deaths from swallowing swords and other items such as neon tubes are described on the internet (www.swordswallow.com/ halloffame.php).

\section{Comparison with endoscopic injury}

The first endoscopy by Adolph Kussmaul in 1868 used mirrors and a gasoline lamp in a sword swallower, ${ }^{4}$ but rigid instruments, with their high rate of perforation, have largely been replaced. ${ }^{5}$ Patients injured during endoluminal procedures tend to be older and have pre-existing disease, the injuries usually complicating therapeutic manoeuvres. ${ }^{67}$ Iatrogenic perforation is sometimes not recognised until an instrument has passed well into the mediastinum of the patient, who is usually not fully conscious, and it tends to occur either adjacent to a lesion or where the pharynx narrows down to the oesophagus at or near Kilian's dehiscence. ${ }^{6}$ Most sword injuries were lower than this level, suggesting that the failure of a straight sword to negotiate the oesophageal lumen as it curves to fit the dorsal kyphosis may contribute to injury.

As in iatrogenic perforation, penetration is the main cause of injury but lacerations and scissoring injuries occur. A sword rarely passes out into the mediastinum and, although an injured swallower may realise that the performance has not proceeded smoothly, the injury may be recognised only when surgical emphysema, pain, or other symptoms develop, and there is often a delay before medical advice is sought.

Many factors, including delay and the size and site of the injury, have a bearing on outcomes. Mortality from iatrogenic perforation is quoted at $10-30 \%,{ }^{8}$ but we did not find any deaths from sword swallowing.

Our 46 respondents collectively had swallowed over 2000 swords in the three months before we contacted them but the complications relate to their professional lifetimes. Although the risk of sustaining life threatening injury is low for an experienced swallower while relaxed and concentrating on swallowing a single sword, the risk over a career is high. The prognosis for a sword swallower who does sustain upper gastrointestinal injury seems better than for patients who suffer iatrogenic perforation.

We thank Steven Kay of Manchester Business School for statistical help and members of the SSAI.

Contributors: BW is guarantor and designed the study. DM (Dan@swordswallow.com) has attended four international conventions arranged by the SSAI, maintains its archive, and has had contact with most known sword swallowers over several years.

Funding: None.

Competing interests: None declared.

Ethical approval: Not required.

1 Scheinin SA, Wells PR. Oesophageal perforation in a sword swallower. Tex Heart Inst J 2001;28:65-8.

2 Martin M, Steele S, Mullenix P, Long W, Izenberg S. Management of oesophageal perforation in a sword swallower: a case report and review of the literature. J Trauma 2005;59:233-5.

3 Devgan BK, Gross CW, McCloy RM, Smith C. Anatomic and physiological aspects of sword swallowing. Ear Nose Throat J 1978;57:445-50.

4 Huizinga E. On oesophagoscopy and sword-swallowing. Ann Otol Rhinol Laryngol 1969;78:32-9.

5 Kubba H, Spinou E, Brown D. Is same-day discharge suitable following rigid esophagoscopy? Ear Nose Throat J 2003;82:33-6.

6 Younes Z, Johnson DA. The spectrum of spontaneous and iatrogenic esophageal injury. J Clin Gastroenterol 1999;29:306-17.

7 Lawrence DR, Moxton RE, Fountain SW, Ohri SK, Townsend ER. Iatrogenic oesophageal perforations: a clinical review. Ann R Coll Surg latrogenic oesophageal perforations: a clinical review. Ann R Coll Surg Engl 1998;80:115-8

Altorjay A, Kiss J, Voros A, Bohak A Nonoperative management of esophageal perforations. Ann Surg 1997;225:415-21.

(Accepted 28 October 2006)

doi $10.1136 /$ bmj. 39027.676690 .55
Access to genitourinary clinics is a hot topic, and we have been working to encourage more men to present for screening for sexually transmitted infections. There is a long standing urban myth that men attending such clinics have to have the "umbrella test." This myth varies little in rendition. The usual description is that something akin to a cocktail umbrella in a closed position is inserted deep into the urethra. This umbrella is then opened out and withdrawn, to the considerable discomfort of the owner of said urethra.

The origins of this myth are obscure-although, no doubt, readers will enlighten us. In fact, asymptomatic men attending our clinic are checked for urethral infections by urine test only; symptomatic men have a swab tipped with cotton inserted a short distance into their urethra, which is relatively painless.

We needed to know if this myth was still prevalent and whether it was deterring patients from accessing our services.

\section{Methods}

To determine patients' expectations and whether action to dispel the myth is needed, we gave brief ques-
Department of Genitourinar Medicine, St Thomas' Hospital, London SE1 7EH

C Bradbeer consultant S Soni specialist registrar A Ekbote senior house officer T Martin senior staff nurse

Correspondence to: C Bradbeer caroline.bradbeer@ gstt.nhs.uk

BMJ 2006;333:1287-8 